\title{
ANÁLISE POPULACIONAL DE ANOMALOCARDIA BRASILIANA (GMELIN, 1791), NA PRAIA DO SACO DA RIBEIRA, UBATUBA, ESTADO DE SÃO PAULO
}

\author{
Y. SCHAEFFER-NOVELLI
}

Instituto Oceanográfico, Universidade de São Paulo, SP, Brasil

\section{SYNOPSIS}

Monthly quantitative sampling of the beach benthic macrofauna was made from June 1972 through December 1974. Determinations of the distribution index, length/dry weight correlation and vertical distribution pattern was also made.

Introdução

A espécie Anomalocardia brasiliana foi escolhida para estudo da dinâmica populacional devido sua importância como bivalve comestível.

Anomalocardia brasiliana, família Veneridae, ocorre das Indias Ocidentais até o Brasil (Abbott, 1974). Pode ser encontrada em baías e enseadas, em fundo arenoso e areno-lodoso a uma profundidade de $5 \mathrm{~cm}$ no substrato (Narchi, 1972; 1974). Barth (1969) assinala a presenca de $A$. brasiliana em fundos de areia ou lodo, fazendo referêncir sobre a ocorrência de pérolas encontradas em alguns espécimens coletados em fundo arenoso.

Pralelamente alguns aspectos ambientais foram examinados e incluídos em trabalhos anteriores, caracterizando a praia do Saco da Ribeira quanto aos aspectos físicos, químicos e sedimentológicos.

\section{Material e Métodos}

O material analisado neste trabalho faz parte da macrofauna bêntica coletada na região entre-marés da praia do Saco da Riheira, enseada do Flamengo, totalizando 193 estações com coletns em 93 pontos, amostrados de junho de 1972 a dezembro de 1974.

Os exemplares de A. brasiliana são provenientes de dois tupos de amostragen.

1 - amostras menssis (junho de 1972 a janeiro de 1974), coletadas por meio de um delimitador retangular com $0,1 \mathrm{~m}^{2}$ de área, amostrando uma coluna de $10 \mathrm{~cm}$ de altura no substrato;

2 - amostras coletadas nos dias de lua cheia e ua nova (novembro de 1972 a dezembro de 1974), coinciderites com maré favorável e $\mathrm{cmm}$ anxílio de um delimitador circular com $0,5 \mathrm{~m}^{2}$ de área, amost

de área, amostrando uma coluna de $0-5 \mathrm{~cm}$ e outra de 5-10 $\mathrm{cm}$ de altura no substrato, em um úrico ponto da praia, na região conhecida por "Porto do Glorioso". A coincidêncin dos períodos de coleta, com as fases de lua cheia e nova, foi assim planejada a fim de ser verificada a veracidade de crença caiçara quanto a variação de abundância do bivalve $A$. brasiliana, nesses períodos.

Os indivíduos obtidos nas coletas do tipo 1 , tiveram o comprimento da concha medido, em milímetros, e para os indivíduos das coletas do tipo 2 foram determinados além do comprimento da concha, os pesos úmido e seco, em gramas. Os exemplares menores que $4 \mathrm{~mm}$, não tiveram seus pesos secos computados, uma vez que as médias deste parâmetro foram muitas vezes quase iguais a zero.

Os animais das duas coleções não foram separados em função do sexo para as diversas análises. Assim, os resultados são relativos a machos e fêmeas, jovens e aduntos.

- material coletado em dois estratos do sedimento (tipo 2 de amostragem), pode ser considerado como uma única amostra, uma vez que a variação do número de indivíduos foi a mesma para os dois intervalos de profundidade (Fig. 1). A única diferença observada diz respeito ans tamanhos dos bivalves, pois na camarla mais profunda a maioria dos indivíduos está compreendida no intervalo entre 1 e $10 \mathrm{~mm}$ de comprimento total.

Mesmo com respeito an peso seco, estes conjuntos de indjvíduos (0-5 e $5-10 \mathrm{~cm}$ de profundidade no substrato), comportaram-se de forms semelhante:

Este trabalho e parte da tese de doutorado apresentada ao Institu to de Biociências da Universidade de São Paulo.

Publ. no 454 do Inst. Oceanogr. da USP.
Estudo Populacional do Bivalve Anomalocardia brasiliana

A análise populacional procura determinar, em uma população biológica, previamente caracterizada, delimitada geograficamente e com o ciclo de vida conhecido, a: distribuição espacial, estrutura quantitativa, interação populacional, dinâmica espacial e quantitativa (Santos, 1978).

\section{Delimitação da população}

Em toda enseada do Flamengo, a única praia com ocorrência de $A$. brasiliana é a do Saco da Ribeira. Este fato pode ser atribuído a fatores extrínsecos, talvez por tratar-se de uma interrelação entre sedimento e condições físico-químicas, caracterizando um ambiente favorável, não existente nas demais praias da enseada.

Devido a possui uma fase planctônica é possível que essa população não esteja totalmente isolada de outras que por ventura possam existir. Neste caso, a dispersão das larvas para as demais praias ficeria a cargo do padrão de circulação local.

\section{Distribuição espacial}

Como os infivíduos vivem enterrados no substrato a distribuição por eles apresentada, num determinado instante, foi feita por meio de rmostragens de sub-volumes de substrato coletados em cada amostra.

O tipo de distribuicão apresentado. foi calculado por meio do indice de distribuição $I=\bar{S}^{2} / \overline{\mathrm{D}}$, onde, $D_{i}$ é o numero de indivíduos por sub-volume de substrato $S^{2}$, a variância de $D_{i}$ e, $\bar{D}_{a}$ média de $\mathrm{D}_{\mathrm{i}}$.

Para os cálculos foram utilizadas amostras correspondentes a uma mesma faixa de praia, tendo sido coletadas num mesmo dia (Fig. 2).

Os resultados obtidos indicam uma tendência à agregacão para os indivíduos que habitam a região de arein preta, enquanto que os coletados no restante da área amostrada, tem uma distribuição mais para o tipo casual. Foi verificado também, não haver influência no tipo de distribuição quanto à faixa de praia amostrada.

Considerando as linhas-de-maré como delimitarloras de faixas de igual nível de exposição, os pontos de coleta localizados nestas faixas podem ser comparados entre sí quanto à densidade de $A$. brasiliana. Neste caso, a variação do número de indivíduos, durante o período de amostragem, apresentou um decréscimo em função do tempo (Fig. 1).

\section{Correlaçăo peso/comprimento}

Os valores correspondentes ao peso seco médio ( $\overline{\mathrm{W}}$ em g) dos indivíduos do bimestre novembro/dezembro de 1972, foram lançados em função do comprimento (L em mm), como aparece na Figura 3 ( 1 ab. I). seri $-v$ linear a relaçao entre $\log W$ e $\log L$ como mostra a Figura 4 , a relação peso/comprimento (Fig. 5), deve ser do tipo $W={ }^{2} \theta$ onde: $\phi$ fator de condicão (mede o grau ae engorda do animal) e $\theta$ constante aproximadamente igual a 3 . $\oint$ e $\theta$, podem ser estimados por regressão linear com a transformação $\log$. log.

Sendo $\theta \cong 3$, bimestraimente estimamos os valores médios de $\phi$. com a expressão $\varphi=\frac{W}{\mathrm{~L}} 3$ e lançamos em gráfico, conforme
Figura 6 . 


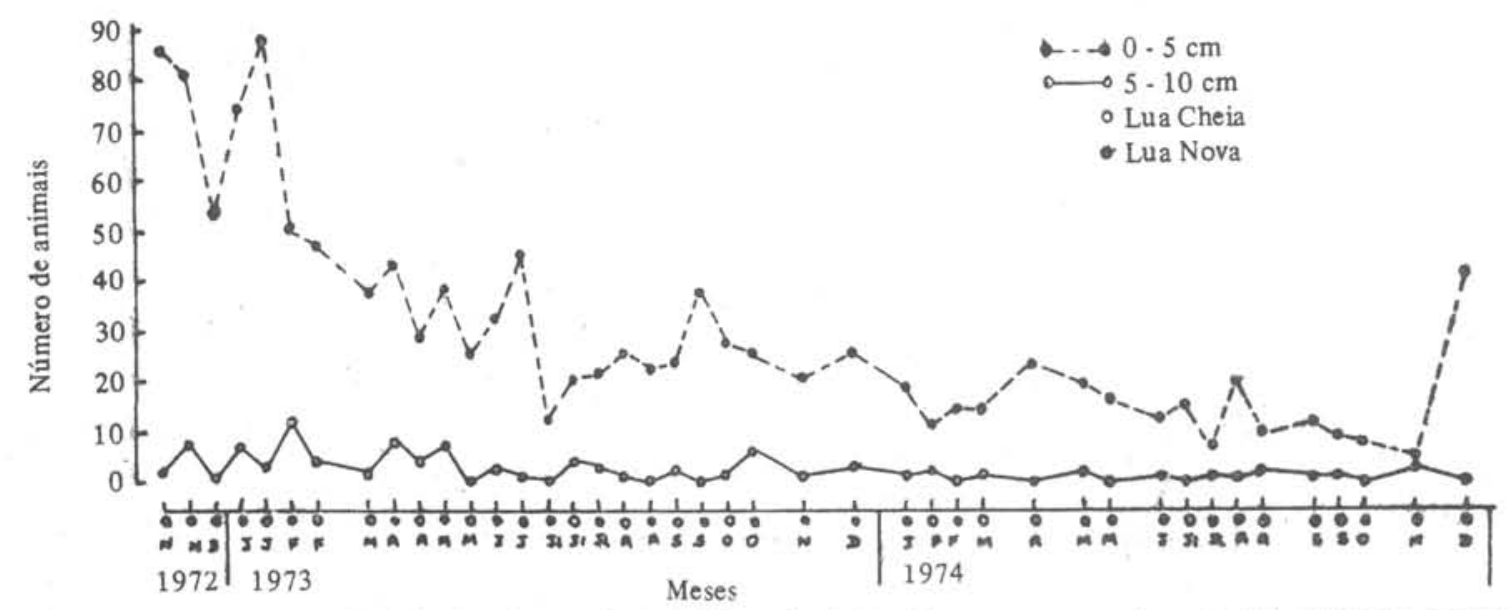

Fig. 1 - Porto do Glorioso. Distribuição do número de indivíduos de $A$. brasiliana para uma coluna de 0-5 e 5-10 cm de profundidade no substrato, em uma área de $0,5 \mathrm{~m}^{2}$ amostrada nas luas nova e cheia de cada mês.

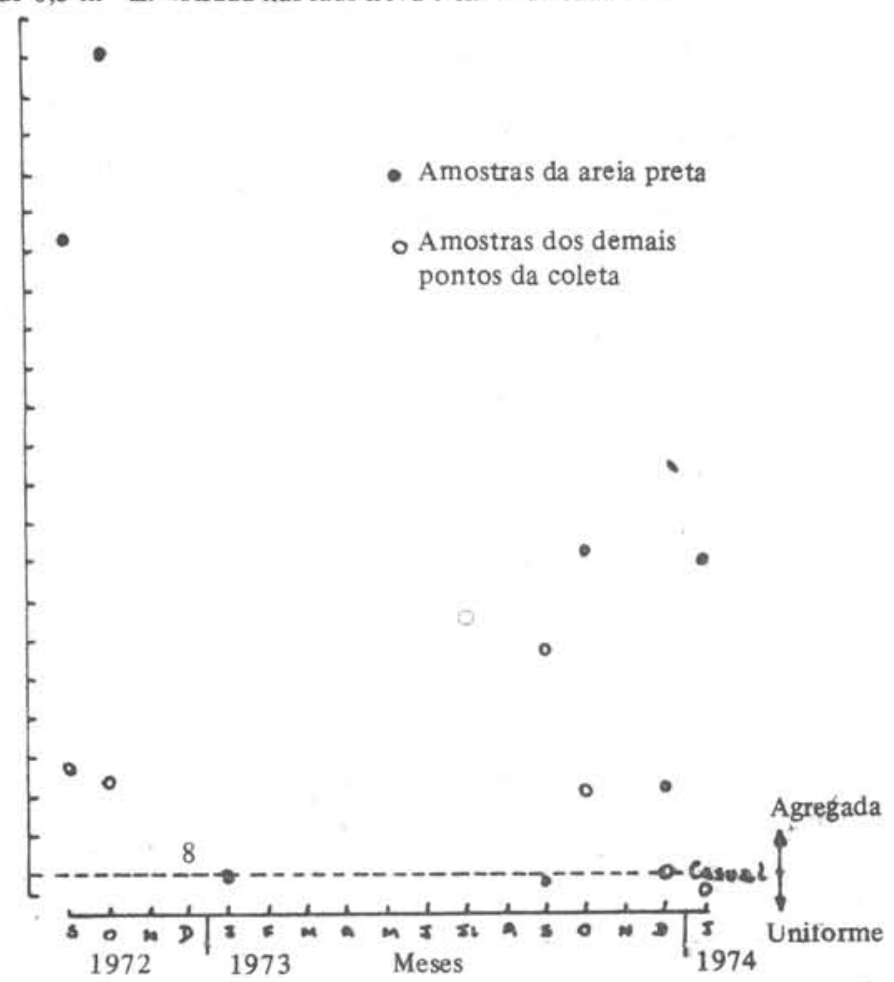

Fig. 2 - Representação gráfica dos resultados obtidos para o tipo de distribuição espacial apresentado por $A$. brasiliana. Amostras de $0,1 \mathrm{~m}^{2}$.

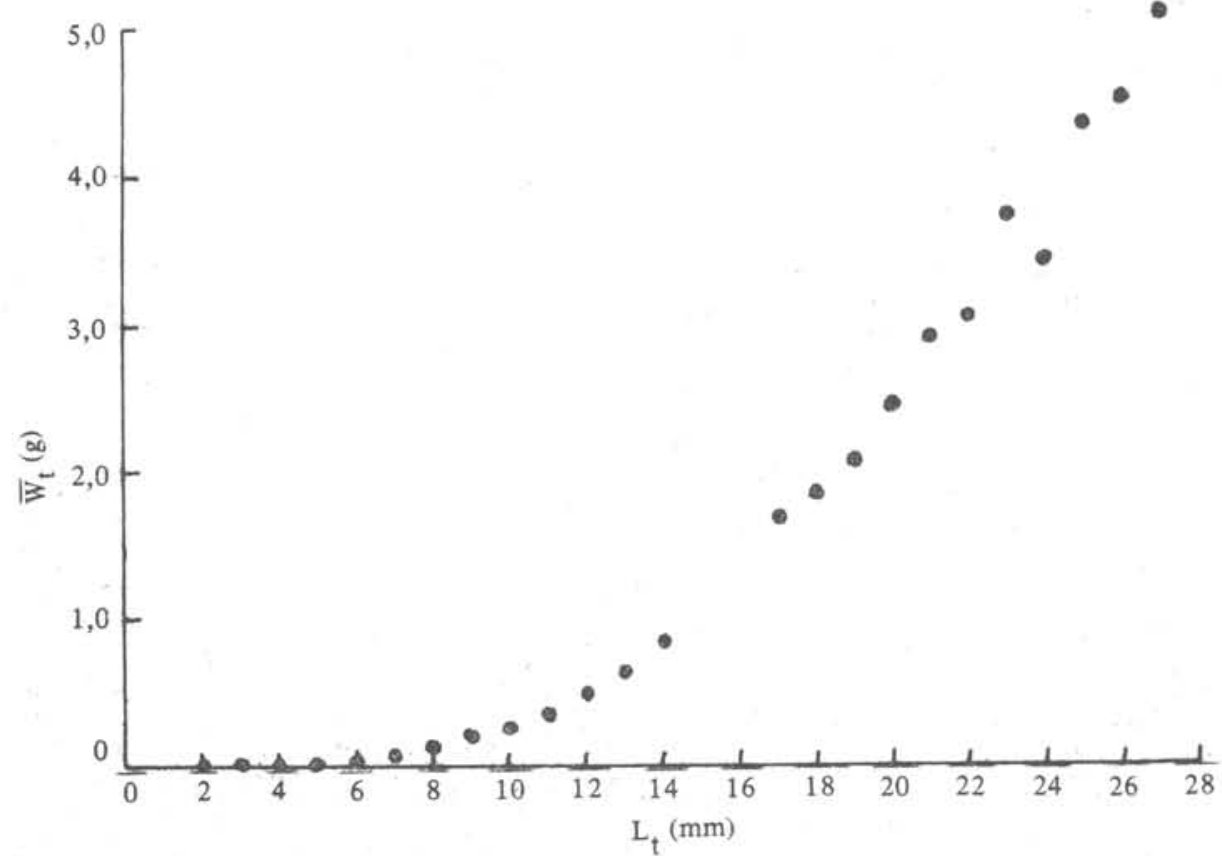

Fig. 3 - Gráfico exemplificando a tendência da variação do peso seco total (g) em relaçăo a do comprimento total (mm); dados relatixos aos exemplares de $A$. brasiliana do Porto do Glorioso, coletados no bimestre novembro/dezembro de 1972 . 


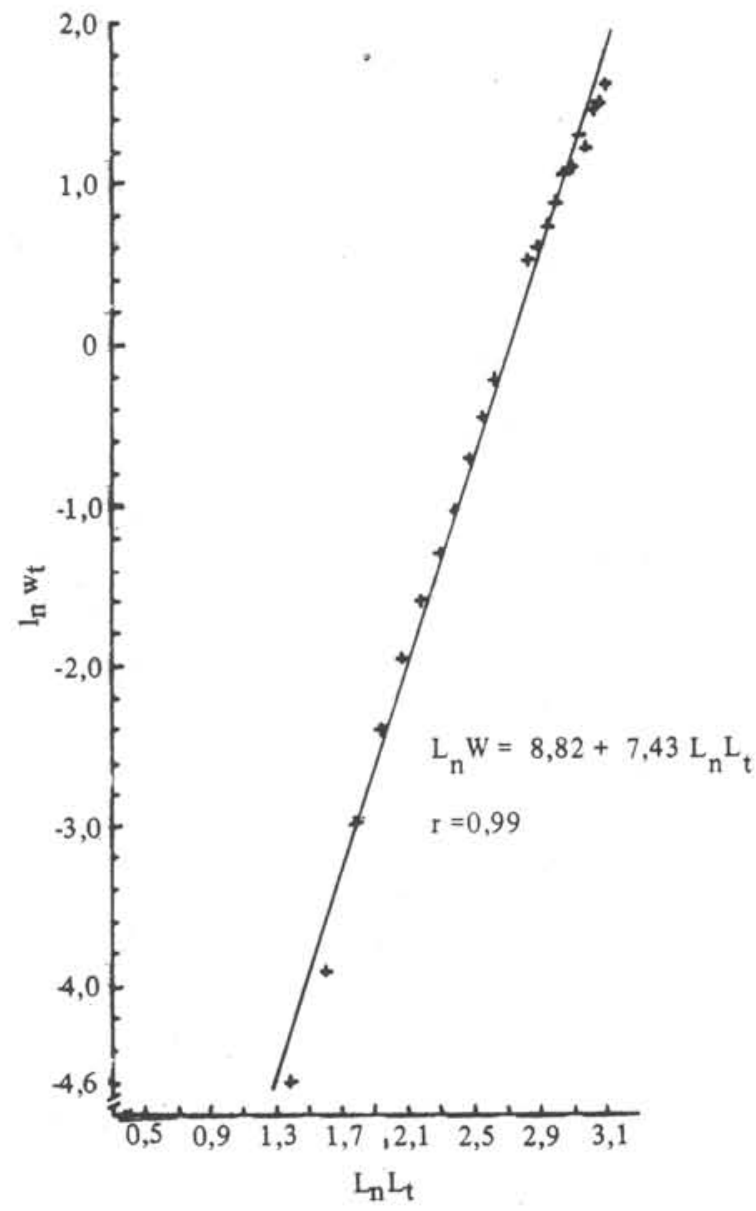

Fig. 4 - Exemplo gratıco da regressão obtida entre o logaritmo do peso seco total $\left(L_{t} w_{t}\right)$ e logarítimo do comprimento total $\left(\mathrm{l}_{\mathrm{L}} \mathrm{L}_{\mathrm{t}}\right)$ ) dados relativos aos exemplares de $A$. brasiliana do Porto do Glorioso, coletados no bimestre novembro/ dezembro de 1972

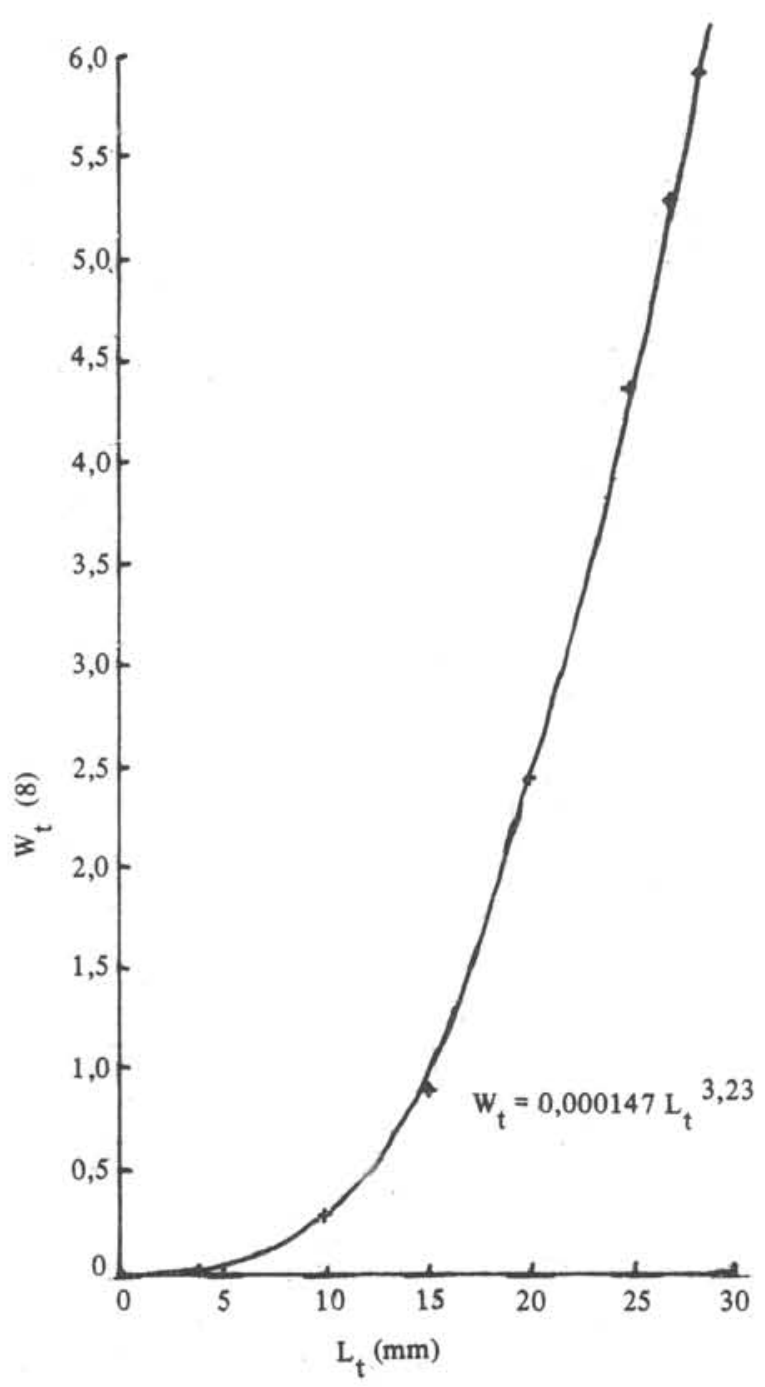

Fig. 5 - Curva calculada para a relação entre peso seco total, (g) e comprimento (mm); dados relativos aos exemplares de $A$. brasiliana do Porto do Glorioso, coletados no bimestre novembro/dezembro de 1972.

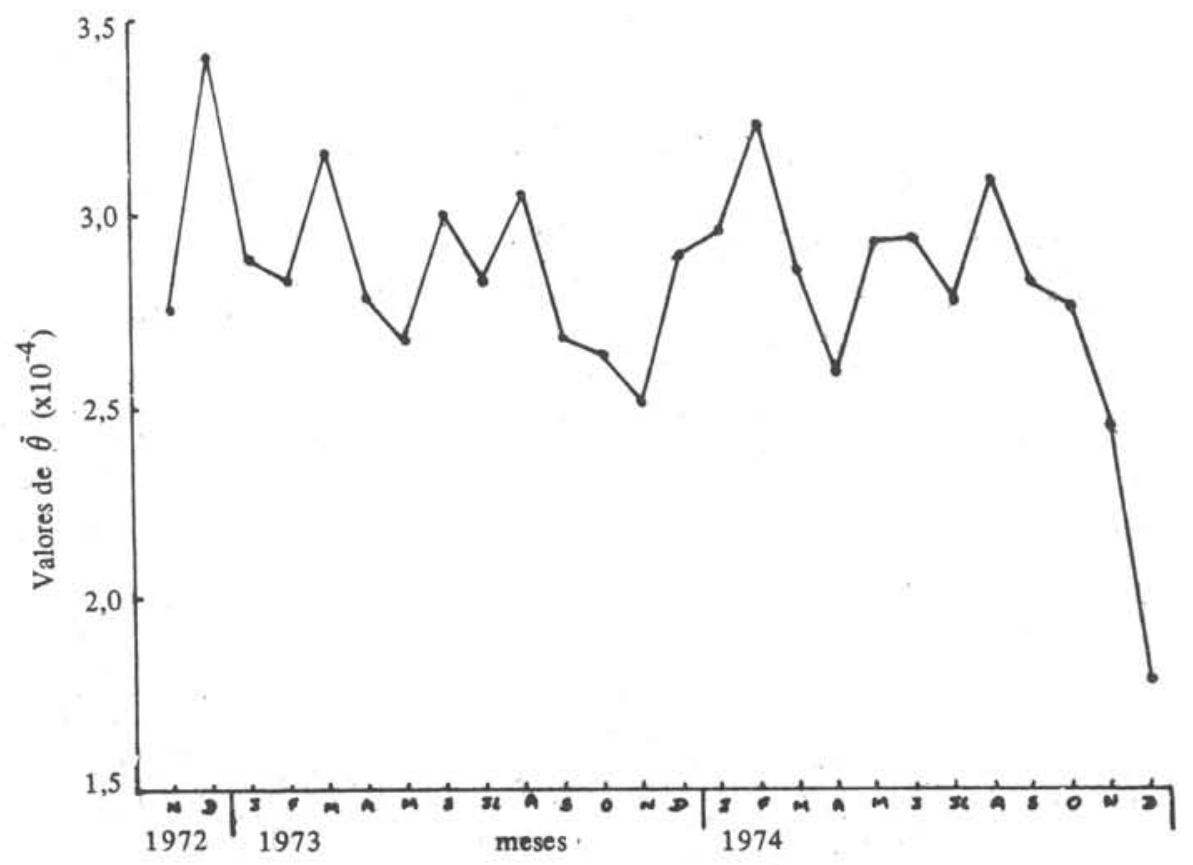

Fig. 6 - Porto do Glorioso, variação estacional dos valores de $\oint$ para $A$. brasiliana da praia do Saco da Ribeira 


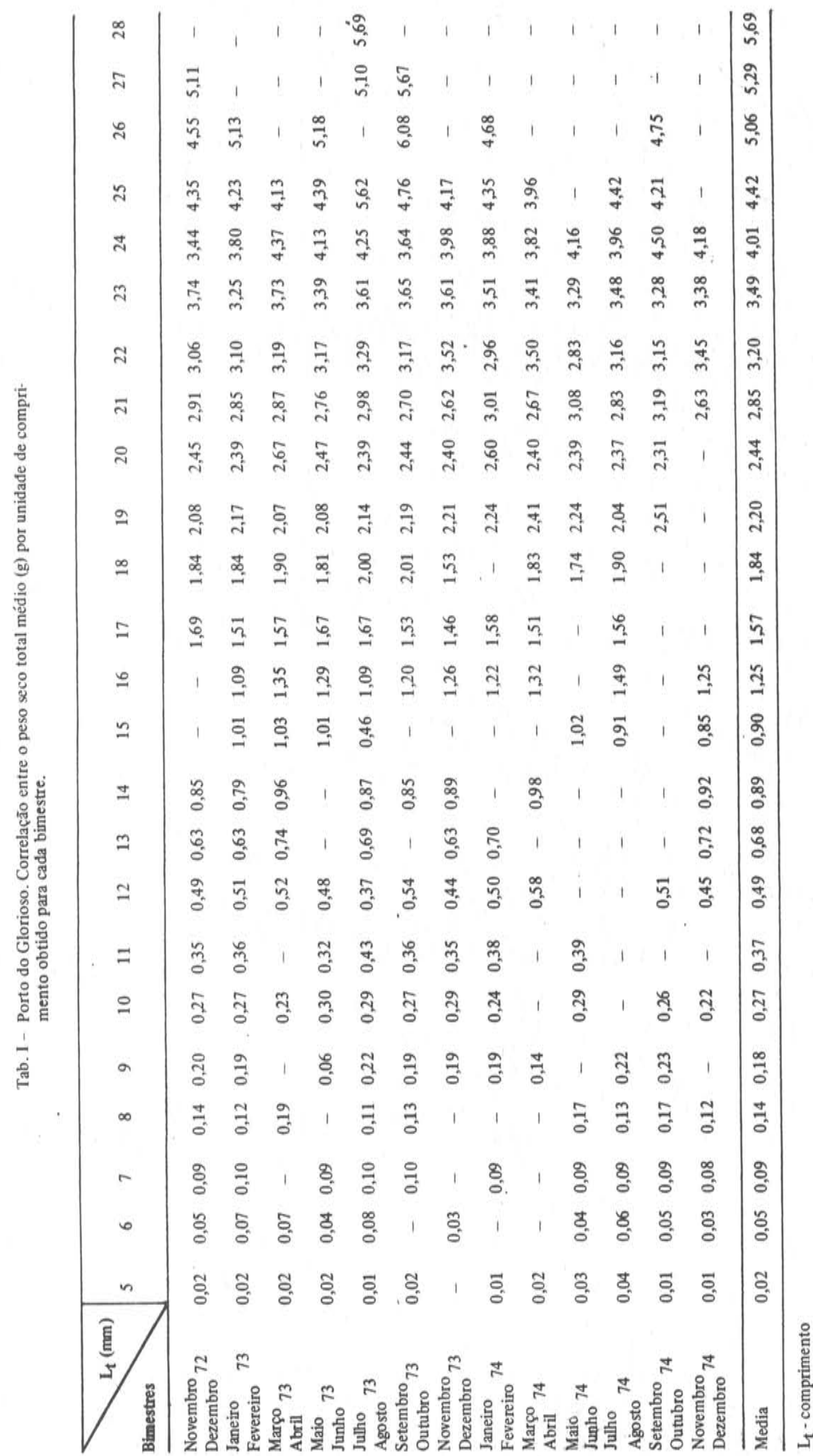


Verificou-se que os valores obtidos não chegam a delimitar uma ou mais épocas do ano quanto aos máximos e mínimos de $\oint \mathrm{e} \theta$. E, como no peso seco total de um bivalve do tipo dos venerídeos, o peso da concha representa a maior parte, este resul. tado talvez sirva para indicar que as condiçōes ambientais realmente não sofrem grandes variaçōes durante $o$ ano.

\section{Conclusð̄es}

Foi observado um decréscimo do número de $A$. brasiliana a partir de outubro de 1973, que talvez esteja condicionado à possibilidade de predação anormal. Tratando-se de espécie comestível surge a idéia de predação humana mas, parece não ser este o único motivo para a queda numérica, pois o mesmo fenômeno foi observado para Macoma cleryana e Tellina (Eurytellina) lineata (Schaeffer-Novelli, 1976).

A espécie de bivalve foi coletada em fundos arenosos e areno-lodoso e principalmente na faixa de praia mais lavada pelas oscilaçōes da maré, tendo ocorrido preferencialmente na região de areia preta e partículas com granulometria média.

$\mathrm{O}$ bivalve $A$. brasiliana mostrou grande resistência à deficiência de suprimento de ar atmosférico, suportando durante o período da baixamar, as condiçōes anóxicas do ambiente redutor encontrado na região de areia preta. Neste ambiente redutor, foram registrados valores iguais a zero para o teor de oxigênio dissolvido na água intersticial.

Os diferentes valores amostrados para temperatura, acompanham as estações do ano. Não foi possível correlacionar a ocorrência dos bivalves com qualquer intervalo preferencial de temperatura. Estes moluscos foram coletados durante todo o período de amostragem tendo suportado amplas variações nos primeiros $10 \mathrm{~cm}$ de substrato, onde a temperatura oscilou de $21,0^{\circ} \mathrm{C}$ (setembro) a $34,0^{\circ} \mathrm{C}$ (janeiro). Esta amplitude de variação de temperatura é moderada pelas condições climáticas e tidais, não chegando a a fetar os animais da endofauna.

O trecho de praia com areia preta se apresenta como um ambiente redutor, com o aparecimento de sulfeto de hidrogênio $\left(\mathrm{H}_{2} \mathrm{~S}\right)$, responsável pela coloração e odor característicos. $\mathrm{O}$ am- biente, favorável aos animais cuja dieta é a de material em suspensão, propicia neste local uma densidade maior da população do bivalve $A$. brasiliana; inclusive quanto à agregação, como ficou demonstrado quando se tratou do tipo de distribuição espacial apresentado.

Quanto ao estudo da distribuição vertical, em relação ao comprimento total, nos diferentes níveis amostrados foi possível verificar que o declive $d a$ praia não chega a exercer influência sobre o padrão apresentado. São encontrados indivíduos grandes e pequenos em qualquer nível da praia, estando unicamente na dependência da época do ano.

Com referência às coletas realizadas com lua nova e lua cheia no "Porto do Glorioso" para $A$. brasiliana, não foi observada ne nhuma variação sensível por ocasião destas duas fases da lua, sugerindo que o maior número de indivíduos coletado seja devido às marés vivas, mascarando o falso juízo de maior abundância de bivalves durante estes períodos.

\section{Bibliografia}

ABBOTT, R. T. 1974. American seashells. New York, Van Nostrand Reinhold, $663 \mathrm{p}$.

BARTH, R. 1969. Sobre a ocorrência de pérolas em moluscos da baía de Guanabara. Publções. Int. Pesq. Mar., (035): $1-15$.

NARCHI, W. 1972. Comparative study of the functional morphology of Anomalocardia brasiliana (Gmelin, 1791) and T7. vela mactroides (Born. 1778) (Bivalvia, Veneridae). Bull. mar. Sci., 22(3) : 643-670.

----- 1974. Aspectos ecológicos e adaptativos de alguns bivalves do litoral paulista. Papéis Avulsos Zool., S. Paulo, 27(19):235-262.

SANTOS, E. P. dos. 1978. Dinâmica de populaçōes aplicada à pesca e piscicultura. São Paulo, HUCITEC/EDUSP, 129 p.

SCHAEFFER-NOVELLI, Y. 1976. Interrelaçōes entre sedimento e bivalves de uma praia areno-lodosa do litoral norte do Estado de São Paulo, Brasil. Mems III Simp. Latınoam. Oceanogr. Biol. (El Salvador), (em preparação). 